\title{
Roger Machado, um português ao serviço dos primeiros soberanos Tudor
}

\section{Francisco Leitão}

\section{(2) OpenEdition}

\section{Journals}

\section{Edição electrónica}

URL: http://journals.openedition.org/medievalista/1515

DOI: 10.4000/medievalista.1515

ISSN: 1646-740X

\section{Editora}

Instituto de Estudos Medievais - FCSH-UNL

Refêrencia eletrónica

Francisco Leitão, «Roger Machado, um português ao serviço dos primeiros soberanos Tudor », Medievalista [Online], 17 | 2015, posto online no dia 01 junho 2015, consultado no dia 06 maio 2019 URL : http://journals.openedition.org/medievalista/1515; DOI : 10.4000/medievalista.1515

\section{(C) IEM}


Título: Roger Machado, um português ao serviço dos primeiros soberanos Tudor Autor(es): Francisco Leitão

Universidade: University of Cambridge

Faculdade e Departamento / Unidade de Investigação: Faculty of History

Código Postal: CB3 9EF

Cidade: Cambridge

País: United Kingdom

Contacto: francisco.leitao@gmail.com

Fonte: Medievalista [Em linha]. Direc. José Mattoso. Lisboa: IEM.

Disponível em: http://www2.fcsh.unl.pt/iem/medievalista/

ISSN: 1646-740X

Data recepção do artigo: 27 de Janeiro de 2014.

Data aceitação do artigo: 8 de Julho de 2014.

\section{Resumo}

O artigo analisa a vida e actividade diplomática de Roger Machado, diplomata português que serviu os reis ingleses entre o final do século XV e o início do seguinte. O maior destaque é dado aos diários escritos pelo próprio como testemunho das embaixadas levadas junto aos Reis Católicos e a João II de Portugal. Os documentos são contextualizados no quadro das relações diplomáticas existentes entre os três países.

Palavras-chave: Roger Machado, diplomacia medieval, relações anglo-portuguesas, relações anglo-espanholas.

\section{Abstract}


The article analyses the life and diplomatic activity of Roger Machado, the Portuguese diplomat who served the English kings between the late XVth and the early XVIth centuries. The main focus is placed upon the diaries written by himself as testimony of the embassy of 1490 to the Catholic Kings of Spain and João II of Portugal. The documents are framed within the diplomatic relations of these countries and can be of use to shed light over the daily life of late medieval diplomacy.

Keywords: Roger Machado, medieval diplomacy, Anglo-Portuguese relations, AngloSpanish relations 


\section{en}

\section{Roger Machado, um português ao serviço dos primeiros soberanos Tudor}

\section{Francisco Leitão}

"The past is a foreign country: they do things differently there." Assim começa o romance The Go-Between (1953), de L. P. Hartley (1895-1972). Mesmo destituída do sentido literário, a frase é susceptível de promover profundo debate historiográfico sobre a nossa percepção de estrangeiro e passado. A segunda parte da frase é, contudo, mais consensual no sentido em que os hábitos de qualquer sociedade têm algo de único e original, tanto quando comparados com o passado que está para trás como com o estrangeiro que está ao lado. Nesse sentido, estrangeiros e historiadores partilham a condição de serem alheios a qualquer determinada sociedade e de fazerem as coisas de modo diferente, com, pelo menos, uma diferença fundamental: o estrangeiro pode contactar directamente com tal sociedade. O presente artigo reflecte sobre uma fonte cujo autor partilhou uma ambígua condição de estrangeiro, mas nativo, face ao Portugal medieval. Os seus diários podem oferecer interessantes contributos por testemunharem o encontro directo de alguém que, tal como o historiador moderno, esteve na posição de observador externo.

Têm passado despercebidas à historiografia portuguesa a vida e carreira de Roger Machado, diplomata que, ao serviço dos reis ingleses entre o final do século XV e o início do século XVI, participou em diversas embaixadas a várias cortes europeias. O assunto também não tem sido tratado em nenhum outro país tocado pela vida deste diplomata. São particularmente relevantes os diários por ele escritos sobre a embaixada inglesa a Castela e Portugal em 1489, na qual Machado participou e que não têm merecido atenção ${ }^{1}$.

\footnotetext{
${ }^{1}$ GAIRDNER, James (ed) - Memorials of King Henry the Seventh. Londres: Rolls Series, 1858, pp. 157199.
} 
Tendo o autor destas linhas constatado tal lacuna no contexto de uma investigação mais ampla, o presente artigo contribui para suprir tal vazio. O texto é assumidamente descritivo mas pretende, por um lado, dar a conhecer uma fonte negligenciada e, por outro, fornecer algum contexto que facilite a sua utilização e compreensão.

$\mathrm{O}$ artigo começa por contextualizar o período no que toca à diplomacia inglesa, ao serviço da qual Roger Machado trabalhou. Num segundo momento, são dedicadas algumas ideias à vida de Machado e, finalmente, num terceiro são abordados os diários de viagens escritos pelo próprio. Neste último tópico, será dada particular atenção à embaixada que visitou as cortes dos Reis Católicos e de D. João, descrevendo o percurso seguido, de acordo com o relato do próprio Machado.

\section{A diplomacia inglesa nos primeiros anos de Henrique VII}

É provável que a viagem que levou Henrique VII a Londres para ser coroado rei de Inglaterra, em 1485, tenha sido apenas a sua segunda visita à capital do reino. $\mathrm{O}$ novo monarca tinha nascido no castelo de Pembroke, uma zona isolada de Gales, e vivido grande parte da sua vida num exílio precário, permanecendo um distante pretendente ao trono até à improvável vitória militar de Bosworth Field, que lhe valeu o reino $^{2}$.

Sem qualquer relevante experiência de liderança ou gestão e desconhecedor do reino que tinha nas mãos, Henrique era não só um dos mais improváveis reis da história medieval inglesa, mas, muito possivelmente, o pior preparado ${ }^{3}$. Ao contrário dos seus antecessores, que tinham mantido grandes ambições no continente, para Henrique VII o desafio primordial era óbvio e modesto: sobreviver no trono e criar uma dinastia ${ }^{4}$.

A favor do novo monarca estiveram os mesmos factores que tinham tornado possível a sua ascensão: a Inglaterra era um reino exausto por dezenas de anos de guerras internas, culminadas com um impopular e violento reinado de Ricardo III e cuja

\footnotetext{
${ }^{2}$ Sobre o reinado de Henrique VII: CHRIMES, S. B. - Henry VII. London: Eyre Methuen, 1972.

${ }^{3}$ GUY, John - Tudor England. Oxford: Oxford University Press, 1988, p. 53.

${ }^{4}$ Para uma análise da relação entre Henrique VII e o seu reino: BRIDGEN, Susan - New Worlds, Lost Worlds. The rule of the Tudors (1485-1603). London, Penguin, 2000, pp. 7-38.
} 
população ansiava por tranquilidade; a violência dos anos anteriores tinha dizimado as mais importantes famílias e a aristocracia tinha um poder fortemente debilitado, incapaz de rivalizar com o monarca; last but not least, de todas as famílias, a real tinha sido a mais atingida e Henrique VII era, finalmente, um rei inglês sem rivais credíveis.

Bafejado pela sorte, o novo monarca poderia ter feito de what we have, we hold o mote do seu governo, particularmente nos anos a que este estudo se refere. Marcado pelos difíceis anos do exílio e rei de uma terra desconhecida, Henrique foi tido como sendo um governante desconfiado e avaro, mas esses traços permitiram dominar a nobreza e estabelecer, de forma sustentada, a paz e uma nova dinastia.

A política externa de Henrique submeteu-se a tais objectivos ${ }^{5}$. Henrique VII sabia bem, por experiência própria, quantas vezes tinham as dinastias inglesas sucumbido perante pretendentes vindos do e apoiados no continente. O monarca inverteu completamente a política externa plantageneta e encaminhou o reino para que este se transformasse de potência continental em marítima. Uma política defensiva que cumpriu a necessidade de evitar apoio externo a qualquer revolta e possibilitou a estabilidade ambicionada.

A embaixada relatada neste artigo data de 1489, poucos anos volvidos desde a tomada do poder e segue a lógica acima mencionada. Este momento da diplomacia inglesa é marcado pela necessidade de Henrique VII ser reconhecido como rei pelos seus pares europeus e pelo apoio à Bretanha na sua falhada luta contra a anexação francesa. Apesar de ter sido apoiado pelos franceses em 1485 e de não desejar qualquer conflito externo, Henrique estava também em dívida para com a Bretanha, onde tinha estado exilado, e receava as consequências económicas e políticas da anexação ${ }^{6}$.

Os Reis Católicos surgiram como natural aliado para tal política e a viagem diplomática às cortes ibéricas pretendia consolidar alianças com o intuito de conter o tal expansionismo francês ${ }^{7}$. O desfecho da Guerra das Rosas tinha feito gorar a hipótese de

\footnotetext{
${ }^{5}$ Uma apreciação global da política externa de Henrique VII (não só do período do artigo mas de todo o reinado) pode ser encontrada em: CHRIMES, S. B. - Henry VII. London: Eyre Methuen, 1972, pp. 272297.

${ }^{6}$ GUY, John - Tudor England. Oxford: Oxford University Press, 1988, pp. 54-55.

${ }^{7} \mathrm{~A}$ bibliografia sobre as relações diplomáticas das duas potências é ampla, mas veja-se, a título de exemplo da política externa de Henrique VII: CURRIN, John - "Henry VII and the treaty of Redon (1489): Plantagenet ambitions and early Tudor foreign policy". in History. The Journal of the Historical Association. Vol. 81 (1996), pp. 343-358; GIRY-DELOISON, Charles - "Money and early Tudor diplomacy. The English pensioner of the French kings (1475-1547)". in Medieval History. Vol. 3 (1993), pp. 128-146. Em relação aos Reis Católicos veja-se, por exemplo: DUOSSINAGUE, José Maria - La
}

Medievalista online № 17 । Ja ne iro - Junho $2015 \odot \mathbb{E}$ - Instituto de Estudos Medieva is 5 www2.fc sh.unl.pt/ie $\mathrm{m} / \mathrm{me}$ die va lista 
um casamento entre Ricardo III e a princesa Joana, irmã de João II, que teria reafirmado as boas relações entre os países, mas Henrique VII iria recorrer a outro matrimónio para reforçar a relação anglo-espanhola. Grosso modo, o tratado assinado em Medina del Campo previa a aliança contra a França, vantagens económicas entre as duas partes e o casamento entre Catarina de Aragão e Artur, filho do rei inglês ${ }^{8}$. Contudo, as complicadas vicissitudes da política europeia da última década do século viriam a inibir a consubstanciação de grande parte do tratado.

Portugal tinha para Henrique VII uma importância bem mais residual. O país tinha sido um útil aliado para a política expansionista inglesa do século anterior e um contraponto à aliança entre Castela e França, mas a nova política defensiva tornava Portugal num elemento menor para a diplomacia inglesa ${ }^{9}$. Não obstante, Henrique VII precisava do reconhecimento dos seus pares e não tinha razão para não procurar cimentar a paz entre os dois países. Com o avançar do reinado, crescerá no monarca inglês a curiosidade pelo Atlântico e o interesse pela actividade portuguesa, mas, diplomaticamente, os Tudor raramente prestaram grande atenção a Portugal. A embaixada de 1489 completou também um tratado cuja simplicidade atesta as reduzidas ambições que a aliança tinha à data ${ }^{10}$.

\section{Um português ao serviço de Henrique VII}

Como tantas vezes acontece com personagens cujo nome cresceu ao longo da vida, os primeiros anos de Roger Machado são, e provavelmente para sempre serão, para nós desconhecidos. Grande parte dos documentos citados ao longo dos próximos

política internacional de Fernando el Católico. Madrid: Espasa-Calpe, 1994; SUARÉZ, Luís - Política Internacional de Isabel la Católica. 6 vols. Valladolid: Instituto "Isabel la Católica" de Historia Eclesiástica, 1965-1972. Sobre as relações entre os dois países: VARELA, Consuelo - Ingleses en España y Portugal (1480-1515): aristocratas, mercaderes e impostores. Lisboa: Colibri, 1998.

${ }^{8}$ URIA MAQUA, Juan; "Los matrimonios de Catalina de Aragón base de la alianza entre Inglaterra y Castilla", in Estudios en Homenaje a Don Claudio Sánchez Albornoz en sus 90 años. Vol. V. Ávila: Anexos Cuadernos de Historia de España, 1990, pp. 403-429.

${ }^{9}$ Uma apreciação das relações entre os dois países, com referência à política matrimonial ibérica e aos diários de Roger Machado pode ser encontrada em: AUBIN, Jean - "D. João II et Henry VII". in Congresso Internacional Bartolomeu Dias e a sua Época: Actas. Vol. I. Porto: Comissão Nacional para a Comemoração dos Descobrimentos Portugueses, 1989, pp. 171-180.

${ }^{10}$ Foedera, conventiones, litterae, etc. ed. T. Rymer. Londres: per A. \& J. Churchill, 1704-35. Vol. XII, p. 378.

Medievalista online № 17। Jane iro - Junho 2015 @ $\mathbb{E M}$ - Instituto de Estudos Me dievais 6 www2.fc sh.unl.pt/ie m/me die va lista 
parágrafos são há muito conhecidos e têm servido para caracterizar a vida de Machado mas o recente trabalho de Gemma Watson traz um par de novas ideias das quais se destaca a possibilidade de participação na revolta de Buckingham e a confirmação da sua origem portuguesa ${ }^{11}$.

É impossível determinar o país ou a data do seu nascimento. A identidade portuguesa pode ser atribuída a partir do nome Machado, que indica uma origem ibérica, mais confirmada pelo uso do brasão de família com os cinco machados dispostos em 2-1-2, que pode ser consultado nos registos ingleses ${ }^{12}$. Os diários de viagem e a maior parte das fontes escritas pelo próprio que nos chegaram encontram-se em francês e têm origem em Inglaterra ou na Flandres, mas sobrevive um rascunho pessoal relativo ao comércio de vinho escrito em português ${ }^{13}$. Desses elementos se pode inferir uma vida com origem portuguesa, mas passada longe da pátria. Fado, afinal, tão português.

A primeira pista que podemos encontrar relativamente ao nosso homem foi identificada por Oliveira Marques, que localiza um Rui Machado na colónia portuguesa de Bruges, quando corria o ano de $1455^{14}$. A tradução de Rui para Roger é directa e, sabendo que o ano da morte do diplomata foi 1510, é provável que se trate do próprio ou de um familiar, possivelmente o pai. Convém ter em conta que Machado seria repetidamente localizado na Flandres ao longo da vida e, mesmo na eventualidade de se tratar do progenitor, podemos assumir que um seguramente jovem Roger Machado não estaria muito longe. É impossível determinar o local de nascimento, mas parece

\footnotetext{
${ }^{11}$ WATSON, Gemma - Roger Machado, a life in objects. Southampton: s.n., 2013, 249 p. A tese de doutoramento não se encontra publicada e agradeço aqui à autora o envio da mesma.

${ }^{12}$ GODFREY, Walter - The College of Arms, Queen Victoria Street, being the Sixteenth and Final Monograph of the London Survey Committee. Londres, London Survey Committee, 1963, pp. 79-80.

${ }^{13}$ College of Arms, Londres, MS Arundel 51, fol. 21. O manuscrito contém um memorando escrito pelo próprio Machado relatando várias das suas actividades. O tal registo em português data de Julho de 1484 e refere-se à compra de vinhos. Está o documento transcrito na tese de Gemma Watson, que também traça o percurso feito pelo manuscrito até aos nossos dias. WATSON, Gemma-Roger Machado, a life in objects. Southampton: (s.n.), 2013, p. 171.

${ }^{14}$ Oliveira Marques participou no colóquio onde Michael Jones apresentou o seu trabalho (conferir nota 29) sobre Roger Machado e terá ali chamado a atenção para tal. Cf. MARQUES, A. H. de Oliveira - “ Notas para a História da Feitoria Portuguesa na Flandres no Século XV". in MARQUES, A. H. de Oliveira - Ensaios de História Medieval. Lisboa: Sá da Costa, 1962, p. 462.

Watson abre depois a possibilidade de se identificar Machado com um "Rodrij Mersado", membro da Guilda de S. Jorge, em Bruges, durante o ano de 1445. Dada a significativa disparidade de nomes e as datas envolvidas, tal parece muito improvável. Machado teria de ser já adulto em 1445, o que é incompatível com a vida activa que manteve e pode ser documentada durante a primeira década do século seguinte.
} 
razoável aceitar que, com ou sem família, um jovem Roger Machado estaria em Bruges em 1455, inserido na rede de comércio internacional.

Até aos finais da década de 70 desse século, temos apenas uma nota, referindo um pagamento recebido no verão de 1471 e que localiza já Machado em Inglaterra ${ }^{15}$. Gemma Watson discute a possibilidade de o português ter sido atraído para Inglaterra pela comitiva que rodeou o exilado Eduardo IV na Flandres e voltou ao país de origem no início de $1471^{16}$. Machado estaria já bem colocado no reino, pois a tal nota refere-o como arauto $^{17}$ e documentação ligeiramente mais tardia reitera múltiplas vezes que teve a dignidade de Leicester Herald até $1483^{18}$. A posição de relativo prestígio sugere que Machado tenha chegado a Inglaterra antes de 1471, mas tal suposição é impossível de comprovar.

Entre 1483 e 1485, Roger Machado parece desaparecer das fontes inglesas, o que pode ser explicado por uma dívida contraída e pela qual falhou em comparecer em tribunal ou por uma possível participação na rebelião de Buckingham que teve lugar em Inglaterra e cujo fracasso o teria obrigado a um breve exílio ${ }^{19}$. Os documentos deste período (entre os quais o escrito em português) não permitem determinar a sua localização, mas no início de 1485 estava na Flandres e poucos meses depois voltava a Inglaterra para ser promovido a Norroy King of $\mathrm{Arms}^{20}$.

A partir deste momento, a vida de Roger Machado estabiliza e servirá sucessivos reis ingleses até à sua morte, em 1510. Neste intervalo será elevado a Clarenceux King of Arms (1494) ${ }^{21}$ e recusará subir ao topo da carreira quando é proposto para Garter Principal King of Arms (1505) ${ }^{22}$. O College of Arms, cujos cargos mais elevados Roger Machado ocupou, tinha sido fundado apenas em 1484 e estava ainda numa fase de

\footnotetext{
15 The National Archives, Londres, E 403/844.

${ }^{16}$ WATSON, Gemma - Roger Machado, a life in objects. Southampton: s.n., 2013, pp. 34-35.

17 Trata-se de uma época de crescente valorização destas posições que culminará na carta real de 1484 , que instituiu o College of Arms, instituição que se mantém em funções até hoje.

${ }^{18}$ British Library, Londres, MS Harley 69, fols 1-2r; National Archives, Londres, C1/66 nº 297.

${ }^{19}$ Gemma Watson discute estas possibilidades na sua dissertação. É aqui que é avançada e defendida a tese de que Roger Machado terá tido algum tipo de participação na rebelião. Roger Machado, a life in objects, pp. 21-27.

${ }^{20}$ GODFREY, Walter - The College of Arms, p. 140.

${ }^{21}$ GODFREY, Walter - The College of Arms, p. 140.

${ }^{22}$ WAGNER, Anthony - Heralds and Heraldry in the Middle Ages: An Inquiry into the Growth of the Armorial Function of Heralds. Londres: Milford - Oxford University Press, 1939, p. 84.
} 
instalação e evolução primária, o que talvez ajude a explicar como alguém vindo de fora tenha subido tão rapidamente a cargos de tal responsabilidade.

Henrique VII é descrito por Polidoro Virgílio como sendo hospitaleiro e generoso com os estrangeiros, não se inibindo de lhes conceder privilégios ${ }^{23}$. O regresso do exílio e a sua ascensão ao trono abriram portas a vários estrangeiros que se foram instalando e progredindo na corte inglesa. John Guy aponta três grupos de onde o monarca escolheu os seus principais servidores: os seus companheiros do exílio na Bretanha; aqueles que o tinham apoiado na batalha de Bosworth Field; os participantes da revolta de Buckingham em $1483^{24}$. É possível que Machado pertencesse tanto ao primeiro como ao segundo grupo e é certo teve contactos com pessoas que seriam facilmente abrangidas por estes critérios ${ }^{25}$. O contexto propiciou a Machado um meio favorável para a sua impressionante ascensão no estrangeiro ${ }^{26}$.

Os membros mais elevados do College of Arms eram usados em múltiplas funções. No caso de Roger Machado, a mais relevante foi a de diplomata, actividade que o levou a receber várias embaixadas e, mais relevante ainda, a participar em várias outras que cruzaram a Mancha em direção a muitas das cortes europeias. Itália, França, Portugal, Espanha, Dinamarca ou o Império Germânico, a todas elas se dirigiu Roger Machado durante aquele quarto de século. Foi nessa dignidade que mais se notabilizou, deixando importantes registos para o historiador. Sobrevivem instruções recebidas do rei para embaixadas em Itália, bem como registos pessoais relativos a viagens efectuadas a Espanha, Portugal e Bretanha ${ }^{27}$.

Os diários escritos por Machado relatando o progresso da tal embaixada a Espanha e Portugal, bem como de outras duas à Bretanha, são documentos de grande valor, mas que raramente têm sido utilizados, pese embora a sua publicação no já

\footnotetext{
${ }^{23}$ VERGIL, Polydore - The Anglica historia of Polydore Vergil. Ed. Denys Hay. London: Royal Historical Society, 1950, pp. 145-147. O próprio Virgílio era de origem italiana e foi recebido na corte de Henrique VII com grande hospitalidade, tendo depois feito carreira naquele reino.

${ }^{24}$ GUY, John - Tudor England. Oxford: Oxford University Press, 1988, p. 56. Que estrangeiros tenham sido beneficiados no processo de organização levado a cabo por Henrique VII é também corroborado por Gunn e Chrimes: GUNN, Steven - "The Courtiers of Henry VII". in English Historical Review. 108 (1993), pp. 23-49; CHRIMES, S. B. - Henry VII. London: Eyre Methuen, 1972, pp. 97-101.

${ }^{25}$ WATSON, Gemma - Roger Machado, a life in objects. Southampton: (s.n.), 2013, p.21-25.

${ }^{26}$ GUNN, Steven - "The Courtiers of Henry VII”. in English Historical Review- 108 (1993), pp. 23-49.

${ }^{27}$ GAIRDNER, James (ed) - Memorials of King Henry the Seventh. Londres: Rolls Series, 1858.
} 
longínquo ano de $1858^{28}$. Roger Machado foi merecendo esporádicas referências na bibliografia inglesa, devido aos cargos desempenhados além-Mancha, mas os trabalhos devotados aos seus diários não esgotam os dedos de uma mão, apesar de tocarem as histórias portuguesa, espanhola, francesa e inglesa ${ }^{29}$.

Os diários sobrevivem num manuscrito da colecção Arundel pertencente ao College of Arms. São originais de Machado escritos em letra bastante legível e sem qualquer decoração ou imagem ${ }^{30}$. Não é clara a finalidade dos textos, pois o rei foi informado dos passos seguidos pela embaixada, mas, atendendo ao seu conteúdo, é razoável pensar que se tratasse de um rascunho utilizado por Machado com vista a uma posterior impressão ou divulgação. O relato salta propositadamente todas as questões mais sensíveis da negociação política, tornando-se assim inofensiva a sua difusão. O manuscrito contém também alguns espaços em branco, sugerindo que o autor pretendia melhorar o texto, bem como pequenas incorrecções ${ }^{31}$ que indicam uma escrita posterior à viagem.

Os diários estão escritos num francês claro, mas não particularmente agradável, razão pela qual se evitará neste texto fazer qualquer citação directa ${ }^{32}$. A edição inicial publicou o texto francês, bem como uma tradução inglesa à qual se juntou, bem mais recentemente, uma espanhola ${ }^{33}$. Neste contexto, uma versão portuguesa não será de

${ }^{28}$ GAIRDNER, James (ed) - Memorials of King Henry the Seventh. Londres: Rolls Series, 1858., pp. 157-222 (versão original) e pp. 328-389 (tradução inglesa).

${ }^{29}$ No que toca à embaixada à Bretanha, o artigo de Michael Jones caracteriza a embaixada e o contexto político de modo a tornar desnecessário abordar o tema neste artigo: JONES, Michael - "Les Ambassades de Roger Machado, le héraut Richmond en Bretagne (1490)". in 1491, La Bretagne. Brest: Centre de Recherche Bretonne et Celtique; Société Archéologique du Finistère, 1992, pp. 147-160. Bello Leon aborda a embaixada à Península Ibérica e fornece uma tradução para Castelhano do diário, mas a análise tem várias incorreçcões e a situação política é descrita de um ponto de vista espanhol e não do inglês, que é o dos diários, pelo que apenas pontualmente se lhe fará referência: BELLO LÉON, Juan Manuel - "Una embajada inglesa a la corte de los Reyes Católicos y su descripcíón en el "Diário" de Roger Machado". in En la España Medieval. vol. 26 (2003), pp. 167-202.

${ }^{30}$ GAIRDNER, James (ed) - Memorials of King Henry the Seventh. Londres: Rolls Series, 1858, p. xxxvii e seguintes para a descrição do manuscrito feita por Gairdner.

${ }^{31}$ Mais à frente se dará conta de como Machado erradamente nos diz que o bispo de Évora era irmão do rei.

${ }^{32}$ Machado tinha sido referido como falando um francês algo "estranho". JONES, Michael - "Les Ambassades de Roger Machado, le héraut Richmond en Bretagne (1490)". in 1491, La Bretagne. Brest: Centre de Recherche Bretonne et Celtique; Société Archéologique du Finistère, 1992, pp. 147-160.

${ }^{33}$ Nas notas anteriores já se referiu a tradução inglesa. A versão espanhola aparece no artigo também já mencionado. 
imperiosa necessidade, sobretudo considerando que, apesar de não ser fácil encontrar as publicações nas bibliotecas nacionais, aquelas estão disponíveis online.

Pelos cuidados tidos por Machado em evitar referências às negociações tidas em ambas as cortes, os diários são sobretudo úteis como testemunho de um viajante medieval, do lado mais prático da actividade diplomática e da vida nas cortes ibéricas.

\section{A embaixada de 1489 a Espanha}

A viagem de 1489 foi precedida de outros contactos diplomáticos, nomeadamente de uma embaixada em sentido inverso no ano anterior. Esses espanhóis acompanhariam o grupo inglês de Machado na viagem entre Inglaterra e a Península Ibérica. Tratava-se de uma missão diplomática espanhola constituída por Rodrigo González de Puebla ${ }^{34}$, Juan de Sepúlveda ${ }^{35}$ e Don Martin de Torres ${ }^{36}$. Todos eles acompanharam o português na viagem que os descreve como sendo, respectivamente, doutor, cavaleiro e capelão ${ }^{37}$.

A embaixada inglesa tinha uma composição algo semelhante ${ }^{38}$ : Thomas Savage $^{39}$, formado em Direito, Richard Nanfan, armado cavaleiro para o efeito, e Roger Machado. Nanfan seguiu acompanhado do seu filho bastardo, referido mais adiante pelo português. Já tinha feito parte de outras embaixadas e seria, assim, um diplomata experimentado e com conhecimento das relações anglo-espanholas. Fica claro pelo diário que, dos três, os dois primeiros tinham um papel principal, cabendo ao último as questões logísticas, a descrição da viagem e, presume-se, a tradução entre as diversas

\footnotetext{
${ }^{34}$ Os nomes dos embaixadores são dados pelo próprio Roger Machado. De Puebla foi um personagem fundamental nas relações anglo-espanholas do tempo, tendo sido embaixador em Londres durante um largo período. De origem judaica, sempre suscitou grande polémica.

${ }^{35}$ Sepúlveda foi também ele usado frequentemente nas relações entre os dois países e participou em várias embaixadas.

${ }^{36}$ Martin de Torres parece menos conhecido mas será talvez descendente do seu homónimo, que foi também diplomata ao serviço de Aragão durante o reinado de Fernando de Antequera.

${ }^{37}$ GAIRDNER, James (ed) - Memorials of King Henry the Seventh. Londres: Rolls Series, 1858, p. 158.

${ }^{38}$ A diplomacia inglesa do período é consistentemente caracterizada como sendo pouco inovadora e as embaixadas seguem as convenções medievais sem diferenças de maior. A grande transformação operada pela afirmação do Estado moderno será provavelmente o estabelecimento de embaixadas permanentes em oposição às viagens diplomáticas mas isso aparecerá muito depois do período em causa e nada há na fonte que sugira esta ou outra importante transformação.

${ }^{39}$ Savage seria o elemento mais importante da comitiva e viria a ser arcebispo de Iorque.
} 
línguas $^{40}$. É fácil perceber as razões que levaram à escolha do português, que estava bem acostumado às viagens de mar para o continente e cujo conhecimento de línguas lhe permitia mediar os contactos. Machado, de resto, teria já feito parte de uma anterior embaixada, pois na Primavera de 1489 recebe 20 marcos para uma viagem a Portugal ${ }^{41}$. No diário, o português omite-se quando lista os embaixadores. Acresce a estes nomes um conjunto de 8 criados que seguiram a comitiva, mas que Roger Machado apenas refere de passagem e sem nenhum tipo de pormenor ${ }^{42}$.

Conforme referido, o conjunto dos embaixadores ingleses e espanhóis deixou a corte rumo a Southampton, de onde partiriam. Zarparam a 19 de Janeiro de 1489, mas rapidamente o mau tempo os forçou a regressar, primeiro a Plymouth e depois a Falmouth, perdendo-se quase um mês com as sucessivas esperas. A atmosfera não deu tréguas durante a travessia, que se provou tormentosa e quase fatal. Finalmente, a 16 de Janeiro de 1489, desembarcaram em Laredo, na costa espanhola ${ }^{43}$.

Dois aspectos sobressaem da travessia. Em primeiro lugar, é estranho que tenha sido tentada numa fase do ano claramente imprópria, sobretudo se tivermos em conta que os embaixadores espanhóis já estavam em Inglaterra há vários meses. É provável que as partes quisessem apressar as negociações do casamento e tenham forçado a viagem. Em segundo lugar, o relato da travessia sublinha como até uma viagem relativamente quotidiana pressupunha elevados riscos. Os relatos de viagens estão repletos de descrições de tempestades, ao ponto de ser questionável a real força das mesmas, mas, tendo Roger Machado considerável experiência no mar, é de crer que a tripulação tenha mesmo corrido risco de vida ${ }^{44}$. Comparando-se esta primeira travessia

\footnotetext{
${ }^{40}$ GAIRDNER, James (ed) - Memorials of King Henry the Seventh. Londres: Rolls Series, 1858, p. 157.

${ }^{41}$ Cf. CAMPBELL, W. (ed) - Materials for a history of the reign of Henry VII from original documents preserved in the Public Record Office. Londres, Longman \& Co, 1877, p. 438.

${ }^{42}$ Bello Leon abre a possibilidade de um pintor, referido como "maestro Antonio, ingles", ter participado na embaixada. Cf. TORRE, Antonio de la - "Maestro Antonio, ynglés, pintor". in Fernando el Católico y la cultura de su tiempo. V Congreso de Historia de la Corona de Aragón. Vol. V. Saragoça: Instituto Fernando el Católico, 1961, pp. 165-172. Parece, contudo, improvável que, nesse caso, Roger Machado não lhe fizesse qualquer referência. O relato da embaixada flamenga de 1428, por exemplo, refere a presença de Van Eyck, apesar de este, à data, ainda não ter a reputação posterior. Cf. VASCONCELLOS, J. (ed.) - Relação da embaixada flamenga (1428-1430) e viagem de Jehan Van-Eyck a Portugal. Porto: s.n., 1897.

${ }^{43}$ GAIRDNER, James (ed) - Memorials of King Henry the Seventh. Londres: Rolls Series, 1858, pp. 159162.

${ }^{44}$ Para uma apreciação dos perigos que a travessia representava à época veja-se CHILDS, Wendy - "The perils, or otherwise, of maritime pilgrimage to Santiago de Compostela in the fifteenth century". in STOPFORD, Jennie (ed.) - Pilgrimage Explored. Woodbridge. D. S. Brewer, 1999, pp. 123-144. É
} 
com a de retorno, mais longa por ter sido feita a partir de Lisboa, mas em condições meteorológicas muito mais favoráveis, devido à época do ano, fica evidente que Machado não tinha por hábito reclamar gratuitamente dos desafios postos pelo mar.

Regressados a terra, mais ficam sublinhadas as dificuldades sentidas por qualquer viajante medieval, mesmo aqueles privilegiados e directamente protegidos pelo poder régio. A casa onde deveriam pernoitar estava lotada e Machado viu-se obrigado a deambular em busca de abrigo, o que eventualmente consegue, junto de um velho conhecido de Southampton ${ }^{45}$. É bem evidente a marca e utilidade de Roger Machado, pois a embaixada prossegue para Burgos, onde é recebida e hospedada por um grupo de mercadores, assumidamente contactos do português que tinha feito comércio entre Inglaterra e Espanha, e mostra a frequente mistura de relações económicas e diplomáticas entre países ${ }^{46}$.

A embaixada ficou em Burgos cerca de uma semana, à espera de notícias dos reis que viriam a garantir as despesas das deslocações ${ }^{47}$. É bem visível como o tratamento prestado a embaixadores em Castela se tornou substancialmente melhor com a ascensão dos Reis Católicos e a estabilização política do país, se compararmos este relato de 1489 com o legado por embaixadas de meados do século $\mathrm{XV}^{48}$. O viajante medieval continua exposto a diversos perigos e abundam as descrições do desconforto sentido, mas o maior controlo e respeito da autoridade régia dava garantias inexistentes algumas dezenas de anos antes ${ }^{49}$.

A viagem prosseguiu depois em direcção a Valladolid sem incidentes de maior, exceptuando um curioso episódio de uma hospedeira pouco acolhedora. Chegados à dita

particularmente expressivo o texto habitualmente referido como "Pilgrim's sea voyage and sea sickness" in Early English Text Society. Londres: Oxford University Press, 1867.

${ }^{45}$ GAIRDNER, James (ed) - Memorials of King Henry the Seventh. Londres: Rolls Series, 1858, p. 162.

${ }^{46}$ GAIRDNER, James (ed) - Memorials of King Henry the Seventh. Londres: Rolls Series, 1858, pp. 163164.

${ }^{47}$ GAIRDNER, James (ed) - Memorials of King Henry the Seventh. Londres: Rolls Series, 1858, p. 166.

${ }^{48}$ Compare-se, por exemplo, este relato com o de Nicolás Lanckman, datado de 1451 e editado em NASCIMENTO, Aires (ed.) - Leonor de Portugal, Imperatriz da Alemanha. Diário de viagem do Embaixador Nicolau Lanckman de Valckenstein. Lisboa: Cosmos, 1992.

${ }^{49}$ Os caminhos castelhanos continuavam a ser, contudo, deveras perigosos para o viajante desprotegido e sem os contactos comerciais e diplomáticos de Roger Machado. Cf. FERNANDEZ LOPEZ, Olga "Caminos y violência en el Madrid medieval". in SEGURA GRAÍÑO, Cristina (ed.) - Caminos y caminantes por las tierras del Madrid medieval. Madrid: Asiciación Cultural Al-Mudayna, 1994, pp. 244250. A bibliografia relativa à crise económica, social e política em Castela durante o século XV é, obviamente, vastíssima, mas para uma apreciação da violência existente veja-se: RUIZ, Teófilo "Violence in late medieval Castille: the case of Rioja". in Revista de História. 133(1995), pp. 15-36. 
localidade, começaram por ser alojados por um mercador conhecido de Machado. O dito não seria capaz de oferecer muito, pois tinha tido a sua propriedade confiscada e os embaixadores acabaram por procurar nova casa ${ }^{50}$. O episódio relativamente insignificante poderia ter grande relevância se se conseguisse ligar o dito comerciante Ruy Gonçalvez de Portilho às famílias de conversos, conforme sugerido por Bello León, mas recente investigação sugere que a questão tenha sido puramente comercial ${ }^{51}$. Não obstante, é estranho que Machado tenha viajado por Espanha num tempo de grande tensão religiosa sem lhe fazer qualquer referência. Sobre os motivos de tal omissão, podemos somente especular, mas se Gonzalez se tratasse de um converso, esta seria certamente propositada $^{52}$.

De Valladolid seguiram para Medina del Campo, onde encontrariam finalmente os reis, mas, pelo caminho, tomaram ainda contacto com uma embaixada de Maximiliano, rei dos Romanos ${ }^{53}$. Percebe-se a crescente ligação da coroa espanhola à política europeia, que leva a uma proliferação de embaixadas na Península, ao ponto de se cruzarem pelas estradas. Nas imediações da corte, estas embaixadas eram sempre recebidas por representantes do rei, que depois acompanhavam e "entretinham" os embaixadores. Também aqui se denota preocupação dos Reis Católicos em bem receber as visitas, pois a comitiva é recebida com pompa por diversos bispos, nobres e outros representantes que denotam a importância dada aos visitantes. Estes são conduzidos aos seus aposentos, exemplarmente preparados ${ }^{54}$.

\footnotetext{
${ }^{50}$ GAIRDNER, James (ed) - Memorials of King Henry the Seventh. Londres: Rolls Series, 1858, pp. 167168.

${ }^{51}$ Bello León consultou os arquivos de Valladolid em busca de estabelecer tal relação, sem sucesso. Na sua tese de doutoramento, Joana Sequeira tratou da história do castelhano, não tendo indicado qualquer questão religiosa: SEQUEIRA, Joana; Production Textile au Portugal à la fin de la Moyen Âge. PortoParis: Faculdade de Letras da Universidade do Porto - École des Hautes Études en Sciences Sociales, 2012, p. 44.

${ }^{52}$ A situação dos judeus na península mereceu comentários muito frequentes dos viajantes estrangeiros. Durante grande parte do século, os comentários surpreendem, por traçarem a Península Ibérica como um local de imensa tolerância, apesar da tensão há muito existente. Uma vez decretada a expulsão dos judeus em 1492, os viajantes mudam de tom, tendência naturalmente acentuada com o massacre de Lisboa de 1506. Além dos relatos anteriormente referidos, vejam-se os contidos em: GARCIA MERCADAL, José (ed.) - Viajes de extranjeros por España y Portugal: Desde los tempos más remotos hasta fines del siglo XVIII. Vol. I. Madrid: Aguilar, 1952. Sobre a fonte relativa ao massacre de Lisboa: YERUSHALMI, Y. H. - The Lisbon massacre of 1506 and the Royal Image in the Shebet Yehudah. Cincinnati: Hebrew Union College - Jewish Institute of Religion, 1976, Appendix A, pp. 69-80.

${ }^{53}$ GAIRDNER, James (ed) - Memorials of King Henry the Seventh. Londres: Rolls Series, 1858, pp. 169170.

${ }^{54}$ GAIRDNER, James (ed) - Memorials of King Henry the Seventh. Londres: Rolls Series, 1858, p. 170.
} 
Três dias depois, a 14 de Março, dá-se finalmente o encontro com os reis ${ }^{55}$. Já ao anoitecer, as numerosas tochas usadas para iluminar caminho e palácio terão produzido um imponente espectáculo, coroado pelos próprios monarcas, cujo vestuário causa grande impressão em Machado. Predomina o dourado, cor do grande pano que decora a sala e ostenta as armas de Castela e Aragão ${ }^{56}$. A mesma cor adorna os monarcas: Fernando, vestido num pano de ouro; Isabel, usando uma muito mais complexa combinação onde predomina o mesmo tom, mas na qual se destacam também pedras preciosas do tamanho de feijões e um grande rubi.

A fusão de diferentes entidades políticas cria sempre promessa de um super poder (não necessariamente consubstanciado) e tem um impacte importante nas mentes da época. Os Reis Católicos souberam potenciar essa imagem através de um impressionante espectáculo de poder ${ }^{57}$.

É particularmente revelador o grande pano dourado que, através das armas de Castela-Aragão, simboliza a união dos dois poderes, funcionando como uma visual declaração de intenções. Roger Machado não era um camponês facilmente impressionável, mas, mesmo habituado à sumptuosa corte inglesa de Henrique VII, não ficou indiferente a esta demonstração de poder. O espectáculo criado na corte não era inocente e surtia o efeito desejado.

Os embaixadores apresentaram as cartas, beijando as mãos dos reis como era costume, e sentaram-se à mesa, ficando Machado atrás. A cerimónia prosseguiu com um discurso de Savage em latim, ao qual respondeu o bispo de Ciudad Rodrigo ${ }^{58}$. O português promete dar o primeiro discurso por escrito, mas acabará por não cumprir a promessa; sobre o segundo, diz, humoradamente, que o velho bispo tinha tão poucos dentes que não se percebia o que dizia ${ }^{59}$. É sabida a dificuldade que Catarina de Aragão

\footnotetext{
${ }^{55}$ Outras fontes confirmam a estadia e partida dos Reis Católicos de Medina del Campo nas datas de Roger Machado. Cf. RUMEU DE ARMAS, Antonio - Itinerario de los Reyes Católicos, 1474-1516. Madrid: Instituto Jerónimo Zurita, 1974.

${ }^{56}$ GAIRDNER, James (ed) - Memorials of King Henry the Seventh. Londres: Rolls Series, 1858, p. 179.

${ }^{57}$ Sobre a moda, vestuário e poder no tempo dos Reis Católicos veja-se: MARTINEZ MARTINEZ, Maria - "La creación de una moda propia en la España de los Reyes Católicos". in Aragón en la Edad Media. Vol. 19 (2006), p. 343-380.

${ }^{58}$ GAIRDNER, James (ed) - Memorials of King Henry the Seventh. Londres: Rolls Series, 1858, p. 172.

${ }^{59}$ Não é inteiramente claro o nível de compreensão que Machado tinha da língua latina, mas é a única vez que este faz semelhante lamento. Ailes sugere ser provável que Roger Machado soubesse latim: AILES, Adrian - "Machado, Roger (d. 1510)". in Oxford Dictionary of National Biography. Oxford: Oxford University Press, 2004. [http://www.oxforddnb.com/view/article/17527, accessed 3 April 2014].
} 
viria a ter para falar com o marido, por terem aprendido pronúncias diferentes de latim e é, portanto, provável que este tipo de discursos feitos em latim entre embaixadores fosse largamente imperceptível para os ouvintes e fizesse somente parte do ritual, sendo o seu conteúdo puramente retórico e algo inconsequente. Não seria de admirar que o problema do velho bispo fosse, além da tal falta de dentes, uma pronúncia desconhecida para os ingleses.

Só no dia seguinte foram os embaixadores chamados de novo à corte para então se tratarem as questões que motivaram a embaixada ${ }^{60}$. Durante uma hora, estiveram reunidos com os reis e embaixadores espanhóis que tinham regressado. Machado omite por completo dos seus diários o conteúdo das conversas, seguramente o mais relevante do ponto de vista político. Não é particularmente surpreendente que o faça; antes como hoje, a discrição é parte importante do trabalho diplomático ${ }^{61}$. A política, no caso concreto o casamento em causa, terá sido acordado entre os dias 26 e 27, visto que Machado refere uma indecisão nesse primeiro dia e acordo total no seguinte. Seria nesse dia assinado o Tratado de Medina del Campo.

A embaixada prossegue com procedimentos comuns a tais situações. Ainda no mesmo dia, os embaixadores encontram-se com o príncipe e a infanta Isabel, ricamente vestidos também eles e acompanhados por um grande número de membros da corte. No dia seguinte, como era também frequente, assistiram à missa a convite dos reis. O dia encerra com um baile, não menos habitual, e onde, curiosamente, se destaca uma portuguesa, aparentemente favorita da rainha. No dia 22, os embaixadores assistiram a jogos em nova demonstração de ostentação e poder feita pelo casal real que permitiu que os embaixadores assistissem ao espectáculo na proximidade da família real. Machado dá pormenores dos vestidos dos reis em cada ocasião e da presença de várias individualidades, apontando, ele mesmo, como os cortesãos espanhóis procuravam imitar as modas francesas o mais rigorosamente possível ${ }^{62}$. Apesar de toda a sumptuosidade da corte ibérica, este não deixa de ser um elemento que descortina falta

\footnotetext{
${ }^{60}$ GAIRDNER, James (ed) - Memorials of King Henry the Seventh. Londres: Rolls Series, 1858, p. 173.

${ }^{61}$ São interessantes as instruções dadas pelo próprio Henrique VII a uma outra embaixada que se dirigiu a Fernando de Aragão, poucos anos mais tarde e onde sublinha a importância dessa virtude. A transcrição pode ser lida em GAIRDNER, James (ed) - Memorials of King Henry the Seventh. Londres: Rolls Series, 1858, pp. 240-281.

${ }^{62}$ GAIRDNER, James (ed) - Memorials of King Henry the Seventh. Londres: Rolls Series, 1858, pp. $176-$ 177.
} 
de originalidade e um certo complexo de inferioridade face a outras sociedades europeias $^{63}$.

Se as viagens eram cansativas e desconfortáveis, a vida de embaixador na corte não podia ser mais suave. O dia acabou com novo serão de dança e, depois de os cortesãos se recolherem, bem passadas as dez horas, reis e embaixadores ficaram sentados para uma abundante ceia que não acabou antes da uma hora da noite ${ }^{64}$.

As descrições dos dias passados na corte são pormenorizadas, mas algo repetitivas. Jogos e danças preenchiam os dias e, se é possível terem sido intercalados por negociações políticas, Machado nada diz sobre isso. O historiador moderno, ao ler tais páginas, tem direito a invejar tão tranquila ociosidade, mas pouco mais tira destas linhas dos diários. Machado, porém, mostra-se reconhecido e desfaz-se em elogios à hospitalidade dos reis, comparando-os, largamente por excesso, aos ingleses. Se a vida de embaixador era doce, também podia acabar por ser substancialmente lucrativa e os representantes de Henrique VII não deixaram a corte espanhola sem um significativo conjunto de presentes em forma de montadas, seda e moedas de prata para os dois embaixadores "séniores" e uma mula e seda tanto para o jovem Nanfran como para Machado $^{65}$. A embaixada ficou em Medina del Campo até ao final de Março de 1489 e daí partiu para Portugal, enquanto outra comitiva espanhola seguia rumo a Inglaterra, indicando que as negociações diplomáticas tinham sido bem mais profícuas do que Machado nos deixa saber. Fica claro, contudo, que os Reis Católicos causaram boa impressão e poderiam esperar que as suas intenções fossem vistas com bons olhos em Inglaterra.

\section{A embaixada a Portugal}

\footnotetext{
${ }^{63}$ Ainda que, sem surpresa, no artigo anteriormente citado, Maria Martinez Martinez trace um quadro bem mais complexo das influências estrangeiras no modo de vestir das elites espanholas. Não obstante, não deixa de ser precioso o testemunho de como um estrangeiro desse tempo teria uma percepção algo diferente da complexa reconstrução operada por um historiador contemporâneo. MARTINEZ MARTINEZ, Maria - "La creación de una moda propia en la España de los Reyes Católicos". in Aragón en la Edad Media. Vol. 19 (2006), pp. 343-380.

${ }^{64}$ GAIRDNER, James (ed) - Memorials of King Henry the Seventh. Londres: Rolls Series, 1858, pp. 179180.

${ }^{65}$ GAIRDNER, James (ed) - Memorials of King Henry the Seventh. Londres: Rolls Series, 1858, p. 184.
} 
A viagem até Portugal durou menos de uma semana, visto que os contactos com a nobreza espanhola permitiram que a viagem continuasse num agradável ritmo de veraneio e a chegada a Portugal se fizesse a 6 de Abril desse ano. Vários viajantes tiveram experiências desagradáveis pela Ibéria, mas a de Roger Machado, passados os percalços iniciais, foi bem amena ${ }^{66}$.

Machado entrou em Portugal precedendo os seus companheiros, como era hábito, para fazer os necessários preparativos. Cruzou a fronteira na zona de Elvas, passando por Vila Viçosa. Machado continua sem razão de queixa da sua viagem, que prossegue tranquilamente e qualquer percalço era rapidamente esquecido pelos presentes que os embaixadores iam coleccionando pelo caminho ${ }^{67}$. No dia 9 de Abril, por exemplo, receberam de Rui D'Abreu (descrito como capitão do castelo de Elvas) vinho, cevada para os cavalos e dois grandes pratos, um de carnes e outro de peixes fritos. Este tipo de presentes em géneros era recebido com grande frequência ${ }^{68}$. O Alentejo não se fez famoso pelo estilo de vida apressado e citadino nem pela cozinha leve e já nesta altura Machado usufruía do que viriam a ser os estereótipos associados à região. A embaixada fez um agradável percurso pelo Alentejo que a levou pelo Redondo, Vidigueira e Portel, onde passaram a Páscoa.

O rei, conforme o costume, enviou uma ampla delegação a Portel para receber os embaixadores, reafirmando os laços existentes entre ele e o seu homólogo inglês. Os embaixadores voltaram a ser presenteados com jogos antes de finalmente prosseguirem, rumo a Beja, ao encontro de João $\mathrm{II}^{69}$. Pelo caminho, a comitiva foi sendo recebida e acompanhada por vários nobres e bispos, tal como tinha sucedido no reino vizinho ${ }^{70}$.

\footnotetext{
${ }^{66}$ GAIRDNER, James (ed) - Memorials of King Henry the Seventh. Londres: Rolls Series, 1858, pp. 184185.

${ }^{67}$ GAIRDNER, James (ed) - Memorials of King Henry the Seventh. Londres: Rolls Series, 1858, pp. 186187.

${ }^{68}$ Gunn refere que Nanfan voltou a Inglaterra com o seguinte acumulado de presentes: um cavalo de guerra, duas mulas, 10 jardas de pano de seda, 40 marcos de prata, uma taça avaliada noutros 40 marcos e contendo moedas estimadas em 200 marcos. Estes elementos coincidem com o relato de Machado e, adicionados a estes géneros recebidos pelo caminho, apontam para uma actividade diplomática deveras rentável. GUNN, Steven - "The Courtiers of Henry VII". in English Historical Review. 108 (1993), pp. 23-49.

${ }^{69} \mathrm{O}$ trabalho de Veríssimo Serrão confirma que João II passou toda a primeira metade de 1489 em Beja: SERRÃO, Joaquim Veríssimo - Itinerários de el-Rei D. João II (1481-1495). Lisboa: Academia Portuguesa da História, 1993.
}

${ }^{70}$ GAIRDNER, James (ed) - Memorials of King Henry the Seventh. Londres: Rolls Series, 1858, pp. 190192. 
A chegada a Beja é celebrada com salvas de canhão e Machado descreve a torre do castelo de Beja, devidamente decorada e onde estaria colocada a artilharia e músicos tocando em homenagem aos visitantes. Estes, acompanhados por 700 ou 800 pessoas (números de Machado), foram levados aos seus aposentos, onde encontraram a ceia pronta e em abundância ${ }^{71}$. A travessia marítima teria tido os seus perigos, mas os embaixadores terão dado o risco por compensado.

A descrição indica que a corte portuguesa, e o monarca em particular, não promovia demonstração de luxo comparável à do reino vizinho. À parte esse elemento, a embaixada decorreu de forma semelhante nas duas cortes, como seria de esperar. Os embaixadores beijaram as mãos dos reis, fizeram-se os habituais discursos, os visitantes foram convidados a assistir às vésperas de S. Jorge com o monarca e, poucos dias depois, decorreram os habituais jogos ${ }^{72}$.

Pelo meio, referido por Machado apenas en passant, João II chamou-os de parte e conversou com os embaixadores. Não temos pormenores da conversa, mas terá sido o momento mais relevante, ainda que seja improvável que assuntos de excessiva importância tenham sido discutidos, visto que a aliança luso-inglesa estava estabelecida e seria apenas uma questão de a ratificar por cortesia. Rui de Pina, ele próprio com experiência diplomática, não faz referência à embaixada, o que denota que esta não terá tido particular impacte em Portugal, visto que o cronista refere a visita de outras personagens ao país ${ }^{73}$.

Acidentalmente, os embaixadores tomaram ainda contacto com o futuro D. Manuel, então duque de Viseu e Beja. É curiosa a omissão no texto original do nome do bispo de Évora, à data D. Afonso, que, erradamente, Machado diz ser irmão do rei ${ }^{74}$.

\footnotetext{
${ }^{71}$ GAIRDNER, James (ed) - Memorials of King Henry the Seventh. Londres: Rolls Series, 1858, pp. 191192.

${ }^{72}$ GAIRDNER, James (ed) - Memorials of King Henry the Seventh. Londres: Rolls Series, 1858, pp. 192194. Passar as vésperas de S. Jorge com o rei pode dar a impressão de um favorecimento incomum, mas João II várias vezes convidou visitantes estrangeiros para ocasiões semelhantes. Veja-se, a título de exemplo, o caso de Nicolau Popplau, que não era sequer um diplomata. Tal diário encontra-se publicado na sua versão espanhola por GARCIA MERCADAL, José (ed.) - Viajes de extranjeros por España y Portugal: Desde los tempos más remotos hasta fines del siglo XVIII. Vol. I. Madrid: Aguilar, 1952, pp. 309-326.

${ }^{73}$ Veja-se a menção feita por Rui de Pina à já referida embaixada de Nicolás Lanckman, por exemplo. PINA, Rui de - Crónicas de Rui de Pina. Introdução e revisão por M. Lopes de Almeida. Porto: Lello \& Irmão, 1977. As referências ao alemão constam na Crónica de D. Afonso V, entre os capítulos CXXXI e CXXXII.

${ }^{74}$ GAIRDNER, James (ed) - Memorials of King Henry the Seventh. Londres: Rolls Series, 1858, p. 192.
} 
Durante a semana seguinte, os embaixadores foram "entretidos" por diversos membros da corte. Jantares, caça e jogos foram novamente os difíceis tormentos sofridos pelos viajantes. Poucos dias depois, os embaixadores voltaram à companhia do rei para finalmente lhe ser conferida a ordem da Jarreteira ${ }^{75}$. Percebe-se pela descrição que João II usava roupas bem mais humildes do que Fernando, tendo, aparentemente, oferecido o seu manto vermelho ao próprio Machado como presente de despedida. Uma vez mais, os embaixadores seriam dispensados apenas depois de recebidos substanciais presentes da parte do rei. Deixariam Beja apenas no final de Maio, mais de um mês depois da chegada à cidade onde João II se encontrava ${ }^{76}$.

O regresso faz-se rumo a Lisboa, por terra até Alcácer do Sal e depois por mar. $\mathrm{Na}$ capital, tiveram a companhia dos vários ingleses que aí viviam e comerciavam e de quem alugaram navios para o regresso a Inglaterra ${ }^{77}$. Os próprios embaixadores aproveitaram a ocasião para fazerem um pouco de negócio, carregando os navios de sal e açúcar. Os laços cruzados entre diplomacia e comércio são evidentes nos relatos das várias viagens.

É pouco claro o episódio que adia a partida de Lisboa, mas Machado alega que o Senhor de Saint-Germain teria capturado navios ingleses, apesar da paz entre os dois países, e os britânicos apenas regressaram quando o francês rumou a sul, em direcção a Tavira, onde estaria João II. A partida de Lisboa fez-se a 3 de Julho, tendo a calma viagem durado pouco mais de duas semanas até à chegada a Inglaterra ${ }^{78}$.

\section{Conclusões}

As embaixadas às cortes ibéricas surtiram o efeito desejado e rapidamente se materializaram em avanços nas relações entre a Inglaterra e os países Ibéricos. O Tratado assinado em Medina del Campo seria ratificado pelo soberano inglês em 1490, unindo as duas potências e acordando o casamento de Artur e Catarina, ainda que as

\footnotetext{
${ }^{75}$ GAIRDNER, James (ed) - Memorials of King Henry the Seventh. Londres: Rolls Series, 1858, p. 193.

${ }^{76}$ GAIRDNER, James (ed) - Memorials of King Henry the Seventh. Londres: Rolls Series, 1858, pp. 194195.

${ }^{77}$ GAIRDNER, James (ed) - Memorials of King Henry the Seventh. Londres: Rolls Series, 1858, pp. 195196.

${ }^{78}$ GAIRDNER, James (ed) - Memorials of King Henry the Seventh. Londres: Rolls Series, 1858, pp. 196197.
} 
condições tenham sido posteriormente revistas em 1492 e 1497. Com Portugal seria renovado o acordo de Windsor, nesse mesmo 10 de Agosto, pelas mãos de João Fogaça e D. Fernando, mestre de Santiago. O próprio Machado terá regressado imediatamente a Portugal, pois recebe dinheiro para cobrir os custos de tal viagem logo a 20 de Agosto, em Windsor, mas nenhum testemunho parece restar dessa viagem ${ }^{79}$.

A vida de Machado não pode ser tida como representativa de um grupo social, no sentido em que esteve envolta em peculiaridades. Certamente poucos portugueses foram tão bem sucedidos e subiram tanto junto de uma corte europeia, mas os dados evidenciados mostram ter havido espaço para mobilidade social para este tipo de homens dispostos a arriscar a sorte e com talento e versatilidade para desempenhar diversas funções, saltando frequentemente de ocupação ${ }^{80}$.

Os seus diários transmitem nas entrelinhas quão distanciado se sentia já de Portugal. Mesmo que tivesse nascido já fora do país, certamente que Machado teria estado em Portugal várias vezes durante a sua actividade comercial, mas os diários têm o tom de quem visita uma terra que não é sua. Ainda assim, sobressaem pormenores, como a não descrição de Lisboa, presença obrigatória em qualquer outro diário de viajantes estrangeiros que por lá passaram, que sugerem uma natural ligação e compreensão do país que outros visitantes estrangeiros não podiam ter.

O texto fornece dados úteis sobre o dia-a-dia nas cortes ibéricas e acerca da vida diplomática medieval. Deve ser lido com algum cuidado no que toca a dados factuais, visto ter sido escrito depois dos acontecimentos, mas merece que se tenha mais em conta entre a historiografia portuguesa quando são tratadas questões relativas à corte e diplomacia.

\section{REFERÊNCIAS BIBLIOGRÁFICAS}

\footnotetext{
${ }^{79}$ A ratificação dos Tratados de Medina del Campo e Windsor, bem como o tal pagamento, ficaram registados nas fontes inglesas. Cf. CAMPBELL, W. (ed.) - Materials for a history of the reign of Henry VII from original documents preserved in the Public Record Office. Londres: Longman \& Co, 1877, pp. 140.

${ }^{80} \mathrm{O}$ caso de Machado, sendo naturalmente especial, não foi completamente único e pode ser comparado ao de Duarte Brandão (Edward Brampton nas fontes inglesas). Cf. ROTH, Cecil - "Sir Edward Brampton: na anglo-jewish aventurer during the wars of the roses". In Transactions (Jewish Historical Society of England). Vol. 16 (1945-1951), pp. 121-127. Jean Aubin, no artigo já citado, recorre frequentemente à actividade de Brandão para narrar as relações entre os dois países. Machado não terá tido uma vida tão itinerante e variada, mas mudou pelo menos um par de vezes de ocupação e país. São vidas peculiares e qualquer comparação deve ser considerada com cautela.
} 


\section{Fontes manuscritas:}

British Library, Londres, MS Harley 69, fols 1-2r

College of Arms, Londres, MS Arundel 51.

National Archives, Londres, C1/66 n²97.

National Archives, Londres, E 403/844.

\section{Fontes impressas:}

CAMPBELL, W. (ed) - Materials for a history of the reign of Henry VII from original documents preserved in the Public Record Office. Londres: Longman \& Co, 1877.

Early English Text Society. Londres: Oxford University Press, 1867.

GAIRDNER, James (ed) - Memorials of King Henry the Seventh. Londres: Rolls Series, 1858.

GARCIA MERCADAL, José (ed) - Viajes de extranjeros por España y Portugal: Desde los tiempos más remotos hasta fines del siglo XVIII. Vol. 1. Madrid: Aguilar, 1952.

NASCIMENTO, Aires Augusto (ed) - Leonor de Portugal, Imperatriz da Alemanha.

Diário de viagem do Embaixador Nicolau Lanckman de Valckenstein. Lisboa: Cosmos, 1992.

PINA, Rui de - Crónicas de Rui de Pina. Introdução e revisão por M. Lopes de Almeida. Porto: Lello \& Irmão, 1977.

RYMER, T. (ed) - Foedera, conventiones, litterae, etc. Londres: per A. \& J. Churchill, 1704-1735.

VASCONCELLOS, J. (ed.) - Relação da embaixada flamenga, 1428-1430 e viagem de Jehan Van-Eyck a Portugal. Porto: s.n., 1897.

VERGIL, Polydore - The Anglica historia of Polydore Vergil. Ed. Denys Hay. London: Royal Historical Society, 1950.

\section{Estudos:}

AILES, Adrian - "Machado, Roger (d. 1510)". in Oxford Dictionary of National Biography. Oxford: Oxford University Press, 2004.

[http://www.oxforddnb.com/view/article/17527, accessed 3 April 2014]. 
AUBIN, Jean - “D. João II et Henry VII". in Congresso Internacional Bartolomeu Dias e a sua Época: Actas. Vol. I. Porto: Comissão Nacional para a Comemoração dos Descobrimentos Portugueses, 1989, pp. 171-180.

BELLO LÉON, Juan Manuel - “Una embajada inglesa a la corte de los Reyes Católicos y su descripcíón en el "Diário" de Roger Machado". in En la España Medieval. vol. 26 (2003), pp. 167-202.

BRIDGEN, Susan - New Worlds, Lost Worlds. The rule of the Tudors 1485-1603. London: Penguin, 2000.

CHILDS, Wendy - "The perils, or otherwise, of maritime pilgrimage to Santiago de Compostela in the fifteenth century". in STOPFORD, Jennie (ed.) - Pilgrimage Explored. Woodbridge: D. S. Brewer, 1999, pp. 123-144.

CHRIMES, S. B. - Henry VII. London: Eyre Methuen, 1972.

CURRIN, John - "Henry VII and the treaty of Redon (1489): Plantagenet ambitions and early Tudor foreign policy". in History. The Journal of the Historical Association. vol. 81 (1996), pp. 343-358.

DUOSSINAGUE, José Maria - La política internacional de Fernando el Católico. Madrid: Espasa-Calpe, 1994.

FERNANDEZ LOPEZ, Olga - “Caminos y violencia en el Madrid Medieval”. in SEGURA GRAÍ̃NO, Cristina (ed.) - Caminos y caminantes por las tierras del Madrid medieval. Madrid: Asociación Cultural Al-Mudayna, 1994, pp. 244-250.

GIRY-DELOISON, Charles - "Money and early Tudor diplomacy. The English pensioners of the French kings (1475-1547)". in Medieval History. vol. 3 (1993), pp. 128-146.

GODFREY, Walter - The College of Arms, Queen Victoria Street, being the Sixteenth and Final Monograph of the London Survey Committee. Londres: London Survey Committee, 1963.

GUNN, Steven - “The Courtiers of Henry VII”. in English Historical Review 108 (1993), pp. 23-49.

GUY, John - Tudor England. Oxford: Oxford University Press, 1988.

JONES, Michael - "Les Ambassades de Roger Machado, le héraut Richmond en Bretagne (1490)" in 1491, La Bretagne. Brest: Centre de Recherche Bretonne et Celtique; Société Archéologique du Finistère, 1992, pp. 147-160. 
MARQUES, A. H. de Oliveira - "Notas para a História da Feitoria Portuguesa na Flandres no Século XV". in MARQUES, A. H. de Oliveira - Ensaios de história medieval. Lisboa: Sá da Costa, 1965, pp. 217-267.

MARTINEZ MARTINEZ, Maria - "La creación de una moda propia en la España de los Reyes Católicos”. in Aragón en la Edad Media. vol. 19 (2006), pp. 343-380.

ROTH, Cecil - "Sir Edward Brampton: an anglo-jewish adventurer during the wars of the roses". in Transactions (Jewish Historical Society of England). Vol. 16 (19451951), pp. 121-127.

RUIZ, Teófilo - "Violence in late medieval Castile: the case of Rioja". in Revista de História 133 (1995), pp. 15-36.

RUMEU DE ARMAS, Antonio - Itinerario de los Reyes Católicos, 1474-1516. Madrid: Instituto Jerónimo Zurita, 1974.

SEQUEIRA, Joana - Production Textile au Portugal à la fin de la Moyen Âge. PortoParis: Faculdade de Letras da Universidade do Porto - Écoles des Hautes Études en Sciences Sociales, 2012.

SERRÃO, Joaquim Veríssimo - Itinerários de el-Rei D. João II (1481-1495). Lisboa: Academia Portuguesa da História, 1993.

SUÁREZ, Luis - Política Internacional de Isabel la Católica. 6 vols. Valladolid: Instituto "Isabel la Católica" de Historia Eclesiástica, 1965-1972.

TORRE, Antonio de la - "Maestro Antonio, ynglés, pintor". in Fernando el Católico y la cultura de su tiempo. V Congreso de Historia de la Corona de Aragón. Vol. V. Saragoça: Instituto Fernando el Católico, 1961, pp. 165-172.

URIA MAQUA, Juan - "Los matrimonios de Catalina de Aragón base de la alianza entre Inglaterra y Castilla". in Estudios en Homenaje a Don Claudio Sánchez Albornoz en sus 90 años. Vol. V. Ávila: Anexos Cuadernos de Historia de España, 1990, pp. 403-429.

VARELA, Consuelo - Ingleses en España y Portugal (1480-1515): aristócratas, mercaderes e impostores. Lisboa: Colibri, 1998.

WAGNER, Anthony - Heralds and Heraldry in the Middle Ages: An Inquiry into the Growth of the Armorial Function of Heralds. Londres: Milford, Oxford University Press, 1939.

WATSON, Gemma - Roger Machado, a life in objects. Southampton: s.n., 2013. 
YERUSHALMI, Y. H. - The Lisbon massacre of 1506 and the Royal Image in the

Shebet Yehudah. Cincinnati: Hebrew Union College-Jewish Institute of Religion, 1976.

\section{COMO CITAR ESTE ARTIGO}

\section{Referência electrónica:}

LEITÃO, Francisco - "Roger Machado, um português ao serviço dos primeiros soberanos Tudor".

Medievalista [Em linha]. No17 (Janeiro - Junho 2015). [Consultado 01.01.2015].

Disponível em

http://www2.fcsh.unl.pt/iem/medievalista/MEDIEVALISTA17/leitao1706.html ISSN 1646-740X.

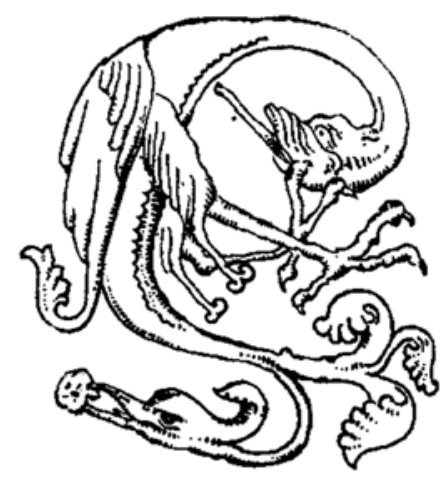

